ORIGINAL ARTICLE

\title{
Evolution the effectiveness of cognitive-behavioral therapy and compassion therapy in resilience and emotional schemas of diabetic patients
}

\author{
FATEMEH JALAYER ${ }^{1}$, MOHAMMAD HATAMI ${ }^{*}$, HADI HASHEMIRAZINI ${ }^{3}$, RITALIYAGHAT $^{4}$ \\ ${ }^{1}$ PhD Student in Health Psychology, Department of psychology, Central Tehran Branch, Tehran, Iran \\ ${ }^{2}$ Associated professor of Psychology, Department of clinical psychology group, Khurazmi University, Tehran. Iran. \\ ${ }^{3}$ Associated professor of Psychology, Department of psychology group, Khurazmi University, Tehran. Iran. \\ ${ }^{4}$ Department of psychology Group, Central Tehran Branch, Tehran. Iran. \\ ${ }^{*}$ Corresponding author: Mohammad Hatami
}

\begin{abstract}
Introduction: Nowadays, comparing the effectiveness of treatment methods to reduce the psychological problems of patients with diabetes is considered by various psychologists. The aim of this study was to compare the effectiveness of compassion therapy and cognitive-behavioral therapy in emotional schemas and resilience in patients with diabetes Type 2

Materials and Methods: The research method is applied in terms of purpose, in terms of implementation of an all-experimental experiment with pre-test, post-test and follow-up design. The statistical population of this study included all diabetic patients referred to Pasteur Hospital in Bam in the second half of 2018 who met the inclusion criteria with a total of 152 people. Sampling method was available. From the statistical population, 45 people were selected and randomly divided into three groups (15 people in cognitive-behavioral therapy group, 15 people in compassion therapy and 15 people in control group). Subjects answered Connor and Davidson Resilience Questionnaires and Leahy Emotional Schemas before and after training. Data were analyzed using covariance .... multivariate method and Tukey's follow-up test.

Results: Findings showed that compassion therapy and cognitive-behavioral therapy improve emotional schemas and increase resilience. The effect of compassion therapy was greater than cognitive-behavioral therapy and maintained its effect over time.

Conclusion: The results showed that compassion therapy had a greater effect on improving emotional schemas and increasing resilience in patients with type 2 diabetes.

Keywords: Cognitive-behavioral therapy, compassion therapy, emotional schemas, resilience
\end{abstract}

\section{INTRODUCTION}

The progressive increase in the incidence and prevalence of chronic diseases worldwide and the high mortality rate and increasing care costs of patients and especially the integral role of psychological factors in the onset, persistence and exacerbation of symptoms of the patients has led to this fact that more emphasis should be placed on psychological aspects. (3) The need to use counseling centers and psychological techniques along with physical interventions is increasing day by day, because counseling and new therapies can effectively reduce psychological symptoms in chronic patients, which is also included in the treatment standards recommended by the American Diabetes Association. (4) Diabetes mellitus is a metabolic disorder in the body whose prevalence is constantly increasing. It is estimated that there are about 285 million people with diabetes worldwide, about $70 \%$ of whom are in developing countries. (5)

Resilience as a phenomenon that occurs quite naturally (6) refers to a dynamic process in which human beings show a positive adaptive behavior when faced with adverse conditions or trauma. (7) This feature is supported, developed, and crystallized with the inner ability of the person and social skills and interaction with the environment as a positive trait. (8) Resilience is defined as positive adaptation in response to adverse conditions and individual differences in reaction and coping with difficult situations (Rutter, 1999 and Block, 2002). Masten, Best, and Garmezy believe that resilience refers to the process of returning to normal functioning after experiencing a stressful or distressing event. (9) Thus, a resilient person processes the unfortunate situation in a more positive way and considers himself capable of coping with it. In addition, researchers believe that resilience is a form of self-healing with positive emotional and cognitive consequences. (10). Studies have shown that in stressful situations, those with high resilience have better mental health than those with lower stubbornness, so resilience is directly related to positive emotions and inversely related to negative emotions. (11) Experiencing positive emotions helps people cope better with everyday stress. Therefore, people who experience more positive emotions are more likely to be resilient to severe events. (12) The concept of emotion in evidence-based psychotherapy, especially in the field of cognitive-behavioral psychotherapy, has become more important in recent years. (13) These theories are based on the principle that schema and attitudes toward emotion may cause different changes in the individual. (14) Leahy has presented his model of emotional schemas based on the concept of emotional processing and inspired by the metacognitive model of emotions. He believes that emotional disorders are often the result of a person's evaluation and interpretation of his feelings and the strategies used to deal with these emotions. (15) Emotional schemas refer to the plans, methods, and strategies used by a person in response to an emotion. (16) Emotional schema models refer to the designs, methods, and strategies used by a person in response to an emotion. 
(17) The model of emotional schemas indicates that people may differ in how they conceptualize their emotions, or in other words, people have different schemas about their emotions. These schemas reflect the ways in which individuals experience emotions, and it is believed that they seek to evoke unpleasant emotions about the appropriate plan for acting or how to act against such emotions. (17) In Leahy's model of emotional schemas, when experiencing an unpleasant emotion, a set of strategies and interpretive processes are employed. The first step in the emergence of an emotion is to pay attention to that emotion, which can include both paying attention and labeling emotions. The second step in Leahy's model is cognitive and emotional avoidance of excitement (Leahy, 2003). This avoidance can occur both naturally and in the form of pathological rupture, pleasure and revelry, consumption of drugs and alcohol, etc. (17) The special value of the emotional schema model is that it directly targets the patient's conceptualization and measures of unpleasant emotions. In general, this model is a form of metacognitive therapy that helps the patient to express his theory about how emotions work, the duration and controllability of emotions, flawed measures to manage emotions and beliefs, and problematic strategies for interpreting judgment and controlling emotions. This model also suggests that the patient's motivational problems may reflect more pervasive problematic perspectives on unpleasant emotions. (15).

Since cognitive-behavioral therapy, including cognitive education in medical diseases, can reduce the need to use medical abstinence services and increase the mental health of patients, so this trend is particularly important for medical and chronic diseases in general and diabetes in particular. (18) Therefore, resilience has been considered in recent decades as one of the main personality structures for understanding motivation, excitement and behavior. Resilience is the ability to adapt the level of control to environmental conditions. (19). In the context of human behavior, resilience is often seen as a trait related to character, personality, and ability to cope, and refers to empowerment, flexibility, the ability to master, or return to normal status after facing intense stress and challenge. (20) As a result of this adaptive flexibility, people with higher resilience have higher self-esteem and are more likely to experience positive emotions in their lives and avoid anxiety sensitivities. (1)

One of the factors associated with adherence therapy is the structure of compassion-focused therapy. People who experience negative events in life generally behave more ruthlessly and critically than their loved ones in the same situation. Self-compassion means that people have the same kindness and care for others as they experience adversity. (21) Studies have also shown the role of compassion in the field of physical health, for example, compassion in reducing the immune and behavioral responses caused by anxiety allergies (22), reducing anxiety sensitivities in HIV patients (23), reducing sexual behaviors, safe and adaptive response to HIV (24), increased health-promoting behaviors (25), and more positive responses to aging are involved. (26)

The CFT focuses on four areas: past and historical experiences, underlying fears, security strategies, and unintended consequences. (27) The structure of compassion therapy is based on an evolutionary approach to psychological functions. According to this approach, compassion motivations and abilities are related to evolved brain systems that underlie attachment, altruism, and compassion behaviors. The natural function of compassion is to create loving behaviors, to provide opportunities for cohesion, security, comfort, participation, encouragement and support. (28)

Therefore, in view of the above, the main question of the research is whether there is a difference between compassion therapy and cognitive-behavioral therapy in emotional schemas and resilience in patients with diabetes?

\section{MATERIALS AND METHOD}

The research method is applied in terms of purpose, and is experimental in terms of implementation of an allexperiment with pre-test, post-test and follow-up design. The statistical population of this study included all diabetic patients referred to Pasteur Hospital in Bam in the second half of 2018 who met the inclusion criteria with a total of 152 people. Sampling method was available. From the statistical population, 45 people were selected and randomly divided into three groups (15 people in the cognitive-behavioral therapy group, 15 people in the compassion therapy group and 15 people in the control group). Subjects answered Connor and Davidson resilience questionnaires and Leahy emotional schemas (15) before and after training.

\section{MATERIALS}

\section{A: Leahy Emotional Schemas Questionnaire}

Leahy (2002) has defined emotional schemas as patterns, methods and strategies that are used in response to an emotion (Biranvand, 2014). Emotional schemas in this study is a score that a person obtains on the scale of Leahy emotional schemas (2009) and its fourteen dimensions (affirmation, comprehensibility, guilt, simplification of emotions, higher values, lack of control, numbness, Gains rationality, continuity, agreement, acceptance of emotions, rumination, expression of emotions and blaming others). This scale has options in the Likert scale that range from one to six. The higher a person's score on this scale, the more negative schemas a person has. This questionnaire has 28 questions in the range of 6 degrees. Its validity and reliability have been confirmed in internal studies including Biranvand study (2014) and its reliability has been obtained equal to 0.81 in Cronbach's alpha coefficient.

\section{B: Connor and Davidson Resilience Questionnaire}

The resilience questionnaire was developed by Connor and Davidson (2003) by reviewing the research resources of the field of resilience in 1991-1999. Psychometric properties of this scale were performed in six groups, general population, primary care patients, psychiatric outpatients, patients with generalized anxiety disorder and two groups of patients with post-traumatic stress disorder. The authors of this scale believe that this questionnaire is well able to distinguish between resilient and non-resilient people in clinical and non-clinical groups and can be used in research and clinical situations. The Connor \& Davidson Resilience Questionnaire consists of 25 items that are 
scored on a Likert scale between zero (completely incorrect) to five (completely correct).

The scoring of the options in this scale is as follows:

Completely incorrect $=0$, Rarely $=1$, Sometimes correct $=$ 2 , Often correct $=3$, completely correct $=4$

Therefore, the range of test scores is between 0 and 100. Higher scores indicate more resilience of the subject. The results of factor analysis indicate that this test has 5 factors: perception of individual competence, trust in individual instincts, tolerance of negative emotions, positive acceptance of change and safe relationships, control and spiritual effects. Expressions related to each subscale: subscale of perception of individual competence: 25-24-2317-16-12-12-11-10, subscale of trust in individual instincts negative emotion tolerance: $20-19-19-18-15-17-6$, subscale of positive acceptance of change and safe relationships: 12-4-5-8, control subscale: 22-21-13, spiritual effects subscale: 9-3. Psychometric properties: External reliability: Connor and Davidson report Cronbach's alpha coefficient of resilience scale 0.89 . Also, the reliability coefficient obtained from the retest method in a 4-week interval was 0.87 . Iranian reliability: This scale has been standardized in Iran by Mohammadi (2005). He used Cronbach's alpha method to determine the reliability of Connor and Davidson resilience scale and reported a reliability coefficient of 0.89 . Connor \& Davidson resilience scale scoring: This questionnaire has 25 questions and its purpose is to measure resilience in different people.

To get the total score of the questionnaire, add the total scores of all the questions together. This score will range from 0 to 100 . The higher the score, the more resilient the respondent will be, and vice versa. The cut-off point of this questionnaire is 50 points. In other words, a score higher than 50 will indicate resilience, and the higher the score, the higher the resilience of the individual, and vice versa.

Table (the content of compassion-based treatment sessions)

Table (the content of cognitive-behavioral group therapy sessions based on instructions (Michael Free, 2005))

\section{Findings}

Descriptive findings: Mean and standard deviation show resilience and emotional schemas in three groups of compassion therapy, cognitive-behavioral and control in pre-test, post-test and follow-up courses. As can be seen, the average scores of the groups in the pre-test vary considerably with the post-test.

Inferential findings: In this section, the information obtained from the implementation of resilience questionnaires and emotional schemas in two stages of pre-test and post-test on the members of the sample group is inferentially analyzed. To measure the effectiveness on the amount of studied variables, analysis of covariance was used. In analysis of covariance, the difference between groups in a variable is measured by controlling one or more other variables that may affect the results. In this analysis, first the pre-test effect is removed from the post-test and then the post-test results are compared. To perform analysis of covariance, its presuppositions must first be examined.
Table 2 shows the results of Levin test for equalization of variance error, since the calculated significance level $\mathrm{F}$ of the variables is greater than 0.05 , thus the assumption of equality of variances is confirmed.

Since the M-box test was not significant for any of the research variables, the condition of homogeneity of variance-covariance matrices was correctly observed. Kolmogorov-Smirnov test was used to evaluate the normality of scores.

Considering that the values of significance levels in each pre-test and post-test are more than 0.05. Data distribution is normal in all three communities.

Hypothesis 1: The effect of compassion therapy and cognitive-behavioral therapy on the emotional schemas of patients with diabetes is different.

Table 1: After examining the presuppositions of repeated measures analysis of variance, repeated measures analysis of variance has been used to investigate the effect of compassion therapy and cognitive-behavioral therapy on emotional schemas. The results of Table 1 show that according to the significance level of the studied tests, which is less than 0.05 , this hypothesis is confirmed. The ETA coefficient indicates that about $39 \%$ of the differences in emotional schema scores are related to the effect of therapies.

Table 2: According to Table 2, the compassion therapy, cognitive-behavioral, and control groups showed the largest differences in emotional schematic scores, respectively.

Hypothesis 2: The effect of compassion therapy and cognitive-behavioral therapy on the resilience of patients with diabetes is different.

Table 3: After examining the presuppositions of repeated measures analysis of variance, this variance was used to investigate the effect of compassion therapy and cognitivebehavioral therapy on resilience. The results of Table 6 show this hypothesis is confirmed according to the significance level of the studied tests, which is less than 0.05. The ETA coefficient shows that $41 \%$ of the differences in resilience scores are related to the effect of treatment methods.

Table 4: According to Table 4, the compassion therapy, cognitive-behavioral, and control groups showed the largest differences in resilience scores, respectively.

\section{DISCUSSION}

Hypothesis 1: The effect of compassion therapy and cognitive-behavioral therapy on the emotional schemas of patients with diabetes is different.

The hypothesis is confirmed. The ETA coefficient indicates that about $39 \%$ of the differences in emotional schema scores are related to the effect of therapies. Based on the results, the compassion therapy, cognitivebehavioral, and control groups showed the largest differences in emotional schematic scores, respectively. Kafami et al. (29) confirmed the effect of cognitivebehavioral programming on well-being and increasing hope in patients with MS. Mr. Bagheri et al. (30) in a study confirmed the effect of cognitive-behavioral therapy on increasing the mental well-being and hope of patients with MS. A study conducted by Massoudi (31) on patients with MS also showed that cognitive-behavioral programming (as 
a practical dimension of realism) has an effect on all aspects of mental health and mental well-being. Shaher et al. (32) confirmed the effect of compassion therapy on recovery, negative emotions, depression and anxiety. Emotional schemas are psychological structures that shape a person's personality and affect their interaction with others, emotional experience, and interpretation of people's reactions. During childhood, emotional schemas, such as a child's learning to interact and regulate emotions, develop through interactions with important caregivers. Through basic activities such as play and feeding, the child begins to experience emotions in the environment and interact with others. Repetition of such interpersonal interactions helps the child to create a unique emotional personality and provides the basis for effective interaction and hope for interpersonal communication in the future. In compassion therapy, one finds that one's experiences are universal and that other human beings have similar experiences, while one finds oneself experiencing some emotions and problems alone and separate from other human beings. In order for people to experience complete self-compassion, it is necessary to have a conscious mind view, in other words, they should not avoid experiencing painful feelings because it is necessary to know their feelings in order to feel self-compassion. In cognitive-behavioral therapy, emphasis is placed on identifying false, negative, and irrational beliefs that affect patients' emotions and behaviors and correcting these underlying beliefs using cognitive and behavioral techniques. Therefore, it can be concluded that both compassion therapy and cognitivebehavioral therapy have a positive effect on emotional schemas, but based on the results of this study, compassion therapy has a greater effect, probably because in compassion therapy one finds a conscious mind view and can better controls and manages his/her negative emotions.

Hypothesis 2: The effect of compassion therapy and cognitive-behavioral therapy on the resilience of patients with diabetes is different.

This hypothesis is confirmed. The ETA coefficient shows that $42 \%$ of the differences in resilience scores are related to the effect of treatment methods. Based on the results, the compassion therapy, cognitive-behavioral and control groups showed the largest differences in resilience scores, respectively. Kafami et al. (29) confirmed the effect of cognitive-behavioral programming on well-being and increasing hope in patients with MS. Mr. Bagheri et al. (30) in a study confirmed the effect of cognitive-behavioral therapy on increasing the mental well-being and hope of patients with MS. A study conducted by Massoudi (31) on patients with MS also showed that cognitive-behavioral programming (as a practical dimension of realism) has an effect on all aspects of mental health and mental wellbeing. In his research, Maslar (33) concluded that cognitive-behavioral therapy courses have a positive effect on life satisfaction. Shaher et al. (32) confirmed the effect of compassion therapy on recovery, negative emotions, depression and anxiety. Resilience not only increases a person's endurance and resilience in the face of adversity, but more importantly maintains and even promotes mental health. Resilience enables people to face the difficulties and hardships of social and professional life, without being harmed, and even to use these opportunities to flourish and develop their personality. Self-compassion increases the clarity and accuracy of self-assessment because one does not need to hide one's flaws and mistakes to avoid making cruel judgments; Also, one does not need harsh selfcriticism to not achieve one's ideal goals and standards; Of course, this does not mean that it passes without attention and corrective action, but self-compassion is associated with accepting responsibility for past mistakes and encouragement and patience for the behaviors needed for the desired goals, so it can increase people's resilience. In cognitive therapy, on the relationship between thoughts, situational triggers, and the formation of emotions such as depression and anxiety, the use of evidence-gathering methods and cognitive distortions - with the aim of making the individual's thoughts more objective; The use of behavioral experiments and the discovery and identification of influential and underlying assumptions and beliefs are emphasized. Therefore, it can be concluded that both compassion therapy and cognitive-behavioral therapy have a positive effect on resilience, but according to the results of this study, compassion therapy has a greater effect, probably because in compassion therapy a person can better faces with his/her problems and mistakes and can increase his/her ability by controlling and managing them and accepting responsibility, and as a result, his/her resilience will increase.

Hypothesis 3: The effectiveness of cognitive-behavioral therapy and compassion therapy on emotional patterns persists over time.

The results showed that there was a significant difference between the mean scores of the two groups of compassion education and cognitive-behavioral therapy in the follow-up phase, i.e. the compassion therapy method acted more effectively on emotional schemas, thus the third hypothesis of the study which was based on the effectiveness Cognitive-behavioral therapy and compassion therapy on emotional schemas remains valid over time. Emotional schemas are psychological structures that shape a person's personality and affect their interaction with others, emotional experience, and interpretation of people's reactions. During childhood, emotional schemas, such as a child's learning to interact and regulate emotions, develop through interactions with important caregivers. Self-compassion in its simplest sense means kindness and compassion for people with themselves. According to many psychologists, compassion is related to self-examination and in another view, personal adequacies, failures and mistakes, as well as facing difficult and painful life situations that are beyond human control. Allowing for self-compassion creates an emotional security for the individual to observe himself without fear of blame and allows him to understand and correct inconsistent patterns of his thoughts, feelings, and behaviors. Therefore, it can be concluded that the effect of treatment methods is stable over time and compassion therapy has a more stable effect than cognitive-behavioral therapy on emotional patterns.

Hypothesis 4: The effectiveness of compassion therapy and cognitive-behavioral group therapy on resilience remains stable over time. 
There is a significant difference between the mean scores of the control group and the two experimental groups of compassion training and cognitive-behavioral therapy in the follow-up phase, meaning that the two treatments have increased the resilience of the subjects. There is a significant difference between therapeutic and cognitive-behavioral therapy in the follow-up phase, i.e. the compassion therapy method has been more effective in increasing resilience. It is even an upgrade. Resilience enables people to face the difficulties and hardships of social and professional life, without being harmed, and even to use these opportunities to flourish and develop their personality. Compassion is a skill that can be taught to someone and then practiced by that person, and the person's physiological systems and immune system are affected. (2). This integrated treatment is derived from the sciences of neuroscience, social psychology, growth, evolution, and Buddhism, as well as many other models of treatment for mental health problems. So compassion can increase resilience and maintain its effect over time. Therefore, it can be concluded that the effect of treatment methods is stable over time and compassion therapy has a more stable effect on cognitive resilience than cognitive therapy.

Therefore, this study showed that compassion therapy and cognitive-behavioral therapy are effective in improving emotional schemas and resilience, although compassion therapy is more effective, so it is recommended to improve the mental health of people with anxiety and emotional problems.

Acknowledgments: This article is taken from the doctoral dissertation of Health Psychology, University of Central Tehran, code 162331138 . We truly thank all the people who helped us in this research.

Conflict of interest: There is no conflict of interest between the authors.

\section{REFERENCES}

1. Connor M, Stewart, S.H., Kushner, M.G. . Introduction to the special issue on "Anxiety Sensitivity and Addictive Behaviors". Addictive Behaviors. 2006;26(2):775-85.

2. Davison S. The expectancy model of fear. San Diego: CA: Academic press; 2008.

3. Finkelstein JF, E. . Using Acceptance and Commitment Therapy to Decrease. High-Prevalence Psychopathology by Targeting Self-Compassion: A Randomized Controlled Trial. Dissertations \& Theses - Gradworks 2000:214.

4. Straub P. From perfectionism to academic adjustment: The mediating role of achievement goals. . Personality and Individual Difference. 2001;49:181-4.

5. Khuwaja RT, T.L; Russell, H. L \& Neal, A.A. Selfcompassion as a moderator of thinness-related pressures' associations with thin-ideal internalization and disordered eating. Eating Behaviors. 2010;17:23-6.

6. Lemey RA. The New Handbook Of Cognitive Therapy. London : Journal of Clinical Psychology. 2001;53:6-41.

7. Suniya $P$. The origins and nature of compassion focused therapy, Visual memory deficit in children with dysgraphia. Perceptual and Motor Skills. 2000;97:1281-8.

8. Diener MR. The effectiveness of cognitive behavioral group therapy on self-concept and body image in burnt women. $\mathrm{J}$ Qazvin Univ Med Sci. 2009;15:45-52.

9. Masten M. Emotional vulnerability as a function of physical activity among individuals with panic disorder. Depress Anxiety. 2001;232:102-6.
10. Garmezy N, Masten, Ann S., Tellegen, A. The protective role of competence indicators in children at risk. Psychological Assessment. 1991:277-84.

11. Tugade A. Hierarchical structure and general factor saturation of the Anxiety Sensitivity Index: Evidence and implications. Psychological Assessment. 2004;9:248-77.

12. Alez G. Consequences of Reduced Representational Distinctiveness and of Temporal Instability on Reading Accuracy in Patients with Dysgraphia due to Orthographic Short-term Memory Damage: A New Case and a Literature Review. . Procedia - Social and Behavioral Sciences. 2005:94:209-10.

13. Rimes A. Educational psychology 9, editor. Boston: Allyn and Bacon; 2010

14. J. LB. Levels of anxiety sensitivity in relation to repressive and selfdeceptivecoping styles. Journal of Anxiety Disorder. 2007;13:601-9.

15. Leahy B. The role of linguistic and visualinformation in spelling: A developmental study. Journal of experimental child psychology. 2009;45:112-36.

16. Leahy $M$. The role of linguistic and visual information in spelling: A developmental study. Journal of experimental child psychology45. 2002;5:112-36.

17. Leahy T. Improvement of Cognitive Function after Carotid Endarterectomy-A New Strategy for the Evaluation of Cognitive Function. Journal of Stroke and Cerebrovascular Diseases. 2003;23:1332-6.

18. Hamid Nejad A. Comparison of Equity between Satisfied and Conflicting Couples. Journal of Family Counseling and Psychotherapy. 2011;3:382-98.

19. Abolghasemi.R A, A., Bahrami F., Fatehizadeh M. . The study of the relationship between the amount of forgiveness and marital conflict of couples in Yazd province. Journal of Family Studies. 2012;3:431-42.

20. Momeni F, Aminalroaya, R., Kazemian, S., Esmaeili, M. Forecasting Distress Tolerance on the Base of the Communication Components of Original Family among Divorces and Non-Divorced Women. Journal of Women and Society. 2015;7:91-107.

21. Neff $O$. Selective processing biases in anxiety-sensitive men and women. Cognition \& Emotion. 2003;12(3):105-34.

22. Pace T, Smits, J., Asper, AJ., Zvolensky, Michael J. Emotional vulnerability as a function of physical activity among individuals with panic disorder. Depression and anxiety. 2009;232(5):102-6.

23. Kemppainen H, Shapiro, J., Rich, R. Facing Learning Disabilities in the Adult Years. Understanding Dyslexia, ADHD, Assessment, Intervention, and Research. New York: Oxford University Press; 2013.

24. Brion NB, Keough, M. E., Mitchell, M. A., Reynolds E. K. MacPherson, L., Zvolensky, M. J., Lejuez, C. W. . Anxiety sensitivity: Prospective prediction of anxiety among early adolescents. Journal of anxiety disorders. 2014;24:503-8.

25. Sirois C, Head, K., Muftuler, L., Su, L., Buss, C., Poggi, E. . Shape of the basal ganglia in preadolescent children is associated with cognitive performance. Neuroimage. 2015;99(1):93-102.

26. Leary MR, Tate, Eleanor B., Adams, Claire E., Batts Allen, Ashley., Hancock, Jessica. Self-compassion and reactions to unpleasant self-relevant events: the implications of treating oneself kindly. Journal of personality and social psychology. 2007;92(5):887.

27. Ashworth E, Rosenblum , S., Aloni, T., Josman, M. Relatioships between hand writing performance and organizational abilities among children with and without dysgraphia: Apreliminary study. Journal Research in developmental disabilities. 2011;11(3):31-5.

28. Depue M, Rosellini, A. J., Fairholme, C. P., Brown, T. A. . Anxeity sensitivity profile: Predictive and in cremental validity. Journal of Anxiety Disorders. 2005;22(4):1180-9. 
29. Kafami A, Zarei, H., Hosseini Henzai, A., Poursalehi Navideh, M., Zeini M. A Comparative Study of Mental Health, Adjustment, and Cognitive Emotion Regulation among Married Women and Divorcees in Yazd City. Journal of Women and Society. 2016;6(2):1-16.

30. AghabagheriSeyyed Gholami F, Jafari, A., Qamari, M. . The effectiveness of group counseling in cognitive-behavioral approach in reducing the symptoms of anxiety sensitivity. woman and family studies. 2013;5(19):115-32.

31. Masoodi A. The role of self-compassion in the general health and academic achievement of the nursing and midwifery students in Mashhad University of Medical Sciences in 2014. Journal of Nursing Education. 2016;10(5):9-16.

32. Shaher JA, Schmidtc, N. B., Hofmannd, S. G., \& Timpano. K. R. . Temporal and structural dynamics of anxiety sensitivity in predicting fearful responding to a $35 \% \mathrm{CO} 2$ challenge. Journal of Anxiety Disorders. 2012;24(4):423-32.

33. Maselar S. Anxiety sensitivity, anxiety frequency and the prediction of fearfulness. Behavior Research and Therapy. 2017;4(3):241-8.

Description of the content of compassion-based treatment sessions

\begin{tabular}{|c|c|c|c|c|}
\hline Expected behavior & Homework & Content & Goals & Session \\
\hline $\begin{array}{l}\text { General familiarity with self- } \\
\text { compassion }\end{array}$ & $\begin{array}{l}\text { Rhythmic } \\
\text { breathing } \\
\text { practice }\end{array}$ & $\begin{array}{l}\text { Basic acquaintance, communication, familiarity } \\
\text { with the general concepts of self-compassion and } \\
\text { empathy }\end{array}$ & $\begin{array}{l}\text { Familiarity with } \\
\text { the general } \\
\text { principles of } \\
\text { compassion- } \\
\text { based therapy }\end{array}$ & $1 \mathrm{st}$ \\
\hline $\begin{array}{l}\text { Dealing with self-critical } \\
\text { thoughts }\end{array}$ & $\begin{array}{l}\text { Answer the } \\
\text { practice } \\
\text { questions "How } \\
\text { do you react to } \\
\text { yourself?" }\end{array}$ & $\begin{array}{l}\text { Self-critical education and its types, encouraging } \\
\text { subjects to examine their personality as self-critical } \\
\text { or compassionate, expressing the causes of self- } \\
\text { criticism and its consequences, providing solutions } \\
\text { to reduce self-criticism }\end{array}$ & $\begin{array}{l}\text { Familiarity with } \\
\text { self-critical } \\
\text { behavior and } \\
\text { thoughts }\end{array}$ & 2nd \\
\hline $\begin{array}{l}\text { Accept your mistakes and } \\
\text { forgive yourself }\end{array}$ & $\begin{array}{l}\text { Prepare a } \\
\text { notebook and } \\
\text { record daily } \\
\text { mistakes }\end{array}$ & $\begin{array}{l}\text { Teaching to accept mistakes without judgment, } \\
\text { stating the reasons for making mistakes, stating } \\
\text { the disadvantages and consequences of not } \\
\text { forgiving, providing solutions for forgiving oneself } \\
\text { when making mistakes }\end{array}$ & $\begin{array}{l}\text { Accept your } \\
\text { mistakes and } \\
\text { forgive } \\
\text { yourself }\end{array}$ & 3rd \\
\hline $\begin{array}{l}\text { Train a sense of human } \\
\text { commonality in the face of self- } \\
\text { destructive feelings }\end{array}$ & $\begin{array}{l}\text { Diary notes } \\
\text { about your } \\
\text { compassion }\end{array}$ & $\begin{array}{l}\text { Teaching mindfulness and its skills along with } \\
\text { practicing physical examination and breathing. } \\
\text { Teaching how to endure and overcome problems, } \\
\text { and accept failure, nurturing and understanding } \\
\text { that others also have flaws and problems. }\end{array}$ & $\begin{array}{l}\text { Perception and } \\
\text { ability to } \\
\text { withstand } \\
\text { difficult } \\
\text { situations }\end{array}$ & 4th \\
\hline Grow a sense of self-worth & $\begin{array}{l}\text { Practice self- } \\
\text { appreciation and } \\
\text { mention your } \\
\text { positive qualities }\end{array}$ & $\begin{array}{l}\text { Teaching self-worth and its advantages, } \\
\text { expressing the disadvantages of low self-esteem } \\
\text { and self-esteem, teaching ways to strengthen self- } \\
\text { esteem }\end{array}$ & $\begin{array}{l}\text { Appreciate } \\
\text { yourself }\end{array}$ & 5 th \\
\hline $\begin{array}{l}\text { Cultivate compassionate } \\
\text { thoughts in yourself }\end{array}$ & $\begin{array}{l}\text { Practice mental } \\
\text { imagery }\end{array}$ & $\begin{array}{l}\text { Teaching the creation of compassionate images } \\
\text { and calming through mental imagery (color image, } \\
\text { place and compassionate characteristics) } \\
\text { Teaching the style of expressing compassion and } \\
\text { applying these methods in daily life }\end{array}$ & $\begin{array}{l}\text { Create } \\
\text { pleasant } \\
\text { feelings }\end{array}$ & 6th \\
\hline $\begin{array}{l}\text { Cultivate compassionate } \\
\text { thoughts in yourself }\end{array}$ & $\begin{array}{l}\text { Practice writing } \\
\text { kind words to } \\
\text { yourself }\end{array}$ & $\begin{array}{l}\text { Teaching the concepts of compassion such as } \\
\text { wisdom, attention, rational thinking, warmth, } \\
\text { support and kindness, teaching the traits of self- } \\
\text { compassion such as motivation, sensitivity, } \\
\text { empathy and kindness }\end{array}$ & $\begin{array}{l}\text { Familiarity with } \\
\text { compassionate } \\
\text { behavior }\end{array}$ & 7th \\
\hline $\begin{array}{l}\text { Awareness of conflicting } \\
\text { thoughts and feelings }\end{array}$ & $\begin{array}{l}\text { Gestalt empty } \\
\text { seat exercise }\end{array}$ & $\begin{array}{l}\text { Teaching inner dialogue between the three self- } \\
\text { defined (dialogue between self-critic, self-critical } \\
\text { and self-compassionate) } \\
\text { In this exercise, each person arranges } \\
\text { conversations between different dimensions of } \\
\text { their existence and communicates them. }\end{array}$ & $\begin{array}{l}\text { Identify } \\
\text { conflicting } \\
\text { emotions }\end{array}$ & 8th \\
\hline self-acceptance & $\begin{array}{l}\text { Practice writing } \\
\text { compassionate } \\
\text { letters }\end{array}$ & $\begin{array}{l}\text { Learning to write a compassionate, the patient } \\
\text { writes a letter to himself / herself because of a } \\
\text { mistake made by a compassionate person, and } \\
\text { points out the shortcomings and weaknesses that } \\
\text { he / she feels about himself / herself. }\end{array}$ & $\begin{array}{l}\text { Self- } \\
\text { understanding } \\
\text { and } \\
\text { acceptance }\end{array}$ & 9th \\
\hline $\begin{array}{l}\text { Applying this treatment method } \\
\text { in daily life }\end{array}$ & $\begin{array}{l}\text { Review of past } \\
\text { exercises }\end{array}$ & $\begin{array}{l}\text { Receive feedback from group members about the } \\
\text { principles taught, review and summarize past } \\
\text { material }\end{array}$ & $\begin{array}{l}\text { Review trained } \\
\text { topics }\end{array}$ & 10th \\
\hline
\end{tabular}


Description of the content of cognitive-behavioral group therapy sessions based on instructions (Michael Free 2005)

\begin{tabular}{|c|c|c|c|c|}
\hline Expected behavior & Homework & Content & Goals & Session \\
\hline $\begin{array}{l}\text { General familiarity } \\
\text { with cognitive- } \\
\text { behavioral therapy }\end{array}$ & & $\begin{array}{l}\text { Familiarity with the training course, session rules, } \\
\text { precise definition of cognitive-behavioral therapy }\end{array}$ & Familiarity with group goals & 1st \\
\hline $\begin{array}{l}\text { Recognize beliefs } \\
\text { and identify negative } \\
\text { spontaneous } \\
\text { thoughts }\end{array}$ & $\begin{array}{l}\text { Relaxation practice, writing life } \\
\text { events based on sequence A } \\
\text { (event) B (negative thoughts) } \\
\text { C (outcome) }\end{array}$ & $\begin{array}{l}\text { Identify possible resistances and methods to } \\
\text { prevent them, relaxation practice, writing life } \\
\text { events based on sequence A (event) B (negative } \\
\text { thoughts) C (outcome) }\end{array}$ & $\begin{array}{l}\text { Categorization, beliefs and } \\
\text { identification of spontaneous } \\
\text { negative thoughts }\end{array}$ & 2nd \\
\hline $\begin{array}{l}\text { Being positive and } \\
\text { having positive } \\
\text { thoughts }\end{array}$ & $\begin{array}{l}\text { Familiarity with the vertical } \\
\text { arrow method, the use of } \\
\text { positive affirmations }\end{array}$ & $\begin{array}{l}\text { Review of the previous session, educational } \\
\text { lecture A: Thought injection B: Familiarity with the } \\
\text { method of vertical arrow, the use of positive } \\
\text { emphasis }\end{array}$ & $\begin{array}{l}\text { Being positive and having } \\
\text { positive thoughts }\end{array}$ & $3 r d$ \\
\hline Belief in beliefs & $\begin{array}{l}\text { Reality analysis, drawing how } \\
\text { negative beliefs relate to each } \\
\text { other }\end{array}$ & $\begin{array}{l}\text { Review of the previous session, educational } \\
\text { lecture A: Beliefs can be changed B: Belief test, } \\
\text { reality analysis, drawing how negative beliefs are } \\
\text { related }\end{array}$ & Degree of belief in beliefs & 4th \\
\hline $\begin{array}{l}\text { Achieve a cognitive } \\
\text { map }\end{array}$ & $\begin{array}{l}\text { Prepare the main list of beliefs } \\
\text { and: Cognitive map, the } \\
\text { impact of positive thoughts } \\
\text { and beliefs }\end{array}$ & $\begin{array}{l}\text { Review of the previous session, educational } \\
\text { lecture A: Preparing the main list of beliefs B: } \\
\text { Cognitive mapping, the impact of positive thoughts } \\
\text { and beliefs }\end{array}$ & Cognitive mapping & 5th \\
\hline Changing beliefs & $\begin{array}{l}\text { (1To accept that negative } \\
\text { beliefs and thoughts can be } \\
\text { changed and it is possible for } \\
\text { people to reconsider beliefs, } \\
\text { test beliefs, analyze reality }\end{array}$ & $\begin{array}{l}\text { Review of the previous session, educational } \\
\text { lecture A: To acceptance that negative beliefs and } \\
\text { thoughts can be changed and it is possible for } \\
\text { people to reconsider beliefs, test beliefs, reality } \\
\text { analysis }\end{array}$ & Revise and change beliefs & 6th \\
\hline $\begin{array}{l}\text { Fostering positive } \\
\text { thoughts }\end{array}$ & $\begin{array}{l}\text { (1Analysis of usefulness 2) } \\
\text { Analysis of homogeneity, } \\
\text { replacing negative thoughts } \\
\text { with positive thoughts and } \\
\text { beliefs and the degree of } \\
\text { belief in positive beliefs }\end{array}$ & $\begin{array}{l}\text { Review of the previous session, educational } \\
\text { lecture A: Utility analysis B: Homogeneity analysis, } \\
\text { replacing negative thoughts with positive thoughts } \\
\text { and beliefs and the degree of belief in positive } \\
\text { beliefs }\end{array}$ & Thinking positive & 7 th \\
\hline $\begin{array}{l}\text { Achieve logical } \\
\text { analysis }\end{array}$ & $\begin{array}{l}\text { Logical analysis of all } \\
\text { schemas, both conditional and } \\
\text { definite }\end{array}$ & $\begin{array}{l}\text { Review of the previous session, educational } \\
\text { lecture A: Logical analysis of all schemas, both } \\
\text { conditional and definite }\end{array}$ & Logical analysis & 8th \\
\hline $\begin{array}{l}\text { Accepting the } \\
\text { opposite belief }\end{array}$ & $\begin{array}{l}\text { (1Preparation of hierarchy 2: } \\
\text { Opposing beliefs }\end{array}$ & $\begin{array}{l}\text { Review of the previous session, educational } \\
\text { lecture A: Preparing the hierarchy B: Opposing } \\
\text { belief }\end{array}$ & Hierarchy of opposing beliefs & 9th \\
\hline $\begin{array}{l}\text { Applying this } \\
\text { treatment method in } \\
\text { daily life }\end{array}$ & Practice change in perception & $\begin{array}{l}\text { Review of the previous session, educational } \\
\text { lecture A: Perceptual change B: Optional cortical } \\
\text { inhibition }\end{array}$ & Optional cortical inhibition & 10th \\
\hline Self-recognition & $\begin{array}{l}\text { Self-punishment - self-reward } \\
\text { - maintenance method }\end{array}$ & $\begin{array}{l}\text { Review of the previous session, educational } \\
\text { lecture A: Self-punishment - self-reward B: } \\
\text { Maintenance method }\end{array}$ & Punishment and reward & 11th \\
\hline $\begin{array}{l}\text { Recognize thoughts } \\
\text { and deal with them } \\
\text { properly }\end{array}$ & $\begin{array}{l}\text { Answer the practice questions } \\
\text { "How do you react to } \\
\text { yourself?" }\end{array}$ & $\begin{array}{l}\text { Assignment review, review program for follow-up } \\
\text { and evaluation after treatment, closing program }\end{array}$ & the final conclusion & 12th \\
\hline
\end{tabular}

Table 1: Results of repeated measures analysis of variance of emotional schemas in the groups of compassion therapy, cognitive-behavioral and control

\begin{tabular}{|l|l|l|l|l|l|l|}
\hline Eta coefficient & Significance level & F & Average squares & Degrees of freedom & Total squares & source \\
\hline 0.39 & 0.011 & 11.26 & 53.07 & 2 & 106.13 & Sphericity assummed \\
\hline 0.39 & 0.026 & 11.26 & 53.07 & 2 & 106.37 & Greenhouse geisser \\
\hline 0.39 & 0.011 & 11.26 & 53.07 & 2 & 106.37 & Huynh feldt \\
\hline 0.39 & 0.031 & 11.26 & 106.37 & 1 & 106.37 & Lower bound \\
\hline
\end{tabular}

Table 2: Comparison of pairwise differences in mean scores of emotional schemas in compassion, cognitive-behavioral and control

\begin{tabular}{|l|l|l|}
\hline Significance level & Mean difference & Group \\
\hline $0 / 001$ & $6 / 55$ & Cognitive-behavioral - control \\
\hline $0 / 001$ & $12 / 72$ & Compassion therapy - control \\
\hline $0 / 001$ & $6 / 17$ & Cognitive-behavioral - compassion therapy \\
\hline
\end{tabular}

Table 3: Results of analysis of variance of repeated measures of resilience in compassion, cognitive-behavioral and control groups

\begin{tabular}{|l|l|l|l|l|l|l|}
\hline Eta coefficient & Significance level & F & Average squares & Degrees of freedom & Total squares & source \\
\hline 0.41 & 0.019 & 9.81 & 64.53 & 2 & 129.06 & Sphericity assumed \\
\hline 0.41 & 0.031 & 9.81 & 64.53 & 2 & 129.06 & Greenhouse geisser \\
\hline 0.41 & 0.019 & 9.81 & 64.53 & 2 & 129.06 & Huynh feldt \\
\hline 0.41 & 0.042 & 9.81 & 129.06 & 1 & 129.06 & Lower bound \\
\hline
\end{tabular}

Table 4: Comparison of pairwise differences in mean resilience scores in compassion therapy, cognitive-behavioral and control groups

Table 4: Comparison of pairwise differences in mean resilience scores in compassion therapy, cognitive-behavioral and control groups
\begin{tabular}{|l|l|l|}
\hline Significance level & Mean difference & Groups \\
\hline $0 / 001$ & $8 / 87$ & Cognitive-behavioral - control \\
\hline $0 / 001$ & $15 / 03$ & Compassion therapy - control \\
\hline $0 / 001$ & $6 / 16$ & Cognitive-behavioral - compassion therapy \\
\hline
\end{tabular}

